\title{
cGMP kinase and food-related behaviours
} Marla B Sokolowski*

\author{
Address: Department of Biology, University of Toronto, Mississauga, Ontario, Canada, L5L 1C6 \\ Email: Marla B Sokolowski* - msokolow@utm.utoronto.ca \\ * Corresponding author
}

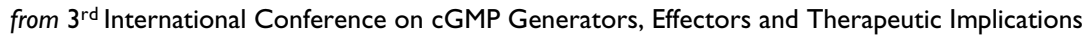

Dresden, Germany. 15-17 June 2007

Published: 25 July 2007

BMC Pharmacology 2007, 7(SuppI I):S46 doi:I0.II86/I47I-22I0-7-SI-S46

This abstract is available from: http://www.biomedcentral.com/I47I-22I0/7/SI/S46

(C) 2007 Sokolowski; licensee BioMed Central Ltd.

The repeated incorporation of common gene activities and pathways into diverse behavioural and environmental contexts throughout evolution is similar to findings in developmental biology showing that principle regulators have been co-opted to generate novel patterns [1]. Nevertheless, such genetic systems must be flexible enough to generate adaptive phenotypes in the midst of unique environmental and developmental constraints. For the foraging gene which encodes a cGMP dependent protein kinase (PKG), variation in gene activity has been associated with distinct alleles within populations in some species (e.g. $D$. melanogaster) and developmental transitions over the lifecycle of single individuals in others (e.g. honeybees [2] and ants). Here we show that the foraging gene in Drosophila also plays a role in behavioural plasticity within the lifetime of the individual. foraging affects food-related locomotion, food intake, responses to food deprivation, energy homeostasis, sucrose responsiveness [3] and learning. Recent immunohistochemical analysis of for expression combined with behaviour genetic analysis enables us to begin to draw parallels between PKG function in invetebrates and mammals.

\section{Acknowledgements}

Research supported by the Canadian Institute of Health Research Grant, the Canada Research Chair Program and a National Institute of Health

Grant to M.B. Sokolowski.

\section{References}

I. Fitzpatrick M, Sokolowski MB: Prospects regarding the evolutionary link between cGMP-dependent protein kinase (PKG) and behaviour. In search of food: Integrative and Comparative Biologys 2004, 44:28-36.
2. Ben-Shahar $Y$, Robichon A, Sokolowski MB, Robinson G: Behaviour influenced by gene action across different time scales. Science 2002, 296:74l-744.

3. Scheiner R, Sokolowski MB, Erber J: Activity of cGMP-dependent protein5kinase (PKG) affects sucrose responsiveness and habituation in Drosophila melanogaster. Learning and Memory 2004, I I:303-3 II. 